\title{
Research on Creative Product Design of Jewelry Design*
}

\author{
Wen Ming Liu ${ }^{1, a \dagger}, \mathrm{YuPu}^{2, \mathrm{~b}}$ \\ ${ }^{1}$ Shenyang Jianzhu University, Shenyang China \\ ${ }^{2}$ Shenyang Jianzhu University Shenyang China
}

\begin{abstract}
With the development of the times and the promotion of technology, people's living standards and aesthetic requirements have also been continuously improved.

Intelligent design enables jewelry to break through its position in the traditional sense It is no longer limited to the handmade production of precious metals. Intelligent design can also be applied to jewelry design. The unlimited choice of materials allows designers to have greater design space and imagination. With the development of fashion trends, jewelry as a kind of decoration, in another way shows the personal quality of life and life attitude. Therefore, the more diversified forms of jewelry design are eclectic, and the pursuit of higher levels and more comprehensive forms to create fashionable and personalized products.
\end{abstract}

\section{Introduction}

Designers usually have some questions: how to show jewelry more changeable? This is a question that every jewelry designer is thinking about. Breaking through products is one of the key points. Breaking conventions and seeking new changes are the common pursuits of jewelry designers. But this change is not just constrained by emerging materials, color matching or new styles. The most important thing is whether this change can bring unlimited changes to the wearer. The innovation of appearance will become the direction for jewelry designers.

Nowadays traditional culture is the trend in China. With the establishment of cultural self-confidence, traditional culture is becoming the new favorite of young people's fashion culture. More and more young people use traditional culture as a new form of expressing their feelings and fashion attitudes. Traditional Chinese culture integrates into life in various ways. How does Chinese traditional culture integrate with jewelry design? As an aesthetic budding on the basis of history, the bronzes of the Shang Dynasty are mainly manifested in the various patterns and shapes of the bronzes of the Shang Dynasty, which contain rich and profound aesthetic charm. This separation of history and culture can shorten the distance between us and tradition through the combination of traditional patterns and jewelry design.

\section{The representative pattern of Shang Dynasty bronze decoration}

\section{1 gluttonous pattern}

The gluttonous pattern is main pattern. It is decorated on the main part, forming an image of big eyes, grinning mouth and sharp fangs. The image of terror in primitive society can be fully expressed, and the power of God can be given to people, and it can better demonstrate the majesty of royal power. Ancient society was underdeveloped with low economy and productivity. The existence of gluttonous patterns is very necessary. The social significance of patterns is greater than its own aesthetic significance.

There are many different interpretations of gluttony. Some people think that gluttony is a monster pattern. Some people think that it is the head of a sheep composed of two chickens. The combination is a homonym of "auspicious", which represents a beautiful meaning. The Shang Dynasty was a society that advocated superstition. Bronze wares were mainly used for sacrifices. Therefore, the gluttony pattern also had the meaning of sacrifice. It should be the image of pigs, cattle, and sheep sacrificed during sacrifice. From this point of view, gluttonous ornamentation is not represented by realism, but an animal image displayed by exaggeration and imagination, which will gradually evolve into other meanings. From the perspective of the artistic design style of bronzes in the Shang and Zhou dynasties, its rich connotation has far-reaching and extensive influence. It created the unique cultural character and artistic style of the Chinese Bronze Age.

\subsection{Hui pattern}

In most cases, it was very popular in the late Shang Dynasty. There are many ways of expression, such as: stamping, carving, painting. The way of expression is mostly continuous and regular composition. It may have evolved from the Neolithic period. However, In the late Shang Dynasty, the probability of the occurrence of Hui 
pattern was very small. However, on the white pottery of the Shang Dynasty, the printed pottery of the Zhou Dynasty, and the original celadon, the appearance of the Hui pattern still occupied a major position. In the Han Dynasty, with the development of bronze ware gradually declined, the Hui pattern on the ceramics gradually disappeared.

There are also various explanations for cloud and thunder patterns. Some people think that early humans left fingerprints on the surface when they made pottery by hand. There are also some subjective explanations, but the more reasonable explanation is that weave patterns are left on the surface. Because the earliest weaving was related to the production of pottery, the woven fabric was first used as the tire, and the surface was burned with fine mud. In primitive society, the woven pattern has become a kind of decoration of pottery, and it has been continuously developed into a commercial Cloud thunder pattern popular in the era.

\subsection{Kuilong pattern}

The Kuilong pattern is also one of the decorative patterns on bronze ware. The pattern on the bronze vessel shows an animal that looks like a Kuilong pattern, which mostly has one horn and one foot, with an open mouth and tail.

For this result, scholars have proved through continuous research and investigation that this result is the reason why primitive humans have viewed things for long time. So this phenomenon is demonstrated. A common body has two horns, or a diagonal line, with a head at each end. This shape was widely used on bronze vessels in the Shang Dynasty and the late Western Zhou Dynasty. The Kuilong pattern on the bronzes usually appears as a dragon-shaped pattern with a long bent body and horns on the head, they are strange in shape.

The application of the Kuilong pattern on bronze vessels is very flexible and lively. Sometimes the gluttony pattern is used as the main pattern and the Kuilong pattern is used as a foil to supplement the blank part except the gluttony pattern. This combination is also an important part of the bronze pattern of the Shang Dynasty. Or the Kuilong pattern alone can form two consecutively arranged decorative patterns, with various bronze patterns.

\section{Symbolic scrutiny of ornamentation}

Every ornamentation can be regarded as a special symbol system, which can provide a huge space for jewelry designers to play. Human beings have entered an era of reading pictures.

In modern road traffic indicator systems, we have seen black and yellow striped patterns to remind drivers to concentrate on their minds. Because people see alternate stripes, they think of dangers in life. In fact, it is a symbolic continuation of people's life experience. The same green color is related to the growth of everything, which often makes people feel refreshed and happy, as if they are in dense jungle and fresh air. Therefore, green is more often used in graphic designs related to life, such as medicine and environmental protection.

In the Shang dynasty, slave owners not only advocated force but also had superstitious ideas, so they changed from polytheism in primitive society to monotheism. It was because people's low productivity at that time could not explain some phenomena scientifically, so some things were abstracted into reflections of people, so the thinking of the ruling class in the Shang Dynasty was mainly manifested in the belief in ghosts and gods.

We must not only show beauty but also reflect its value. In this era of pursuing traditional culture, the bronze ornamentation can reproduce the beauty of the past after the designer's processing and beautification. For the designer, every new exploration will also improve himself, and hope that through the bronze ornamentation The research and development of 5 .

\section{The application of symbolic elements in the bronze decoration of the Shang Dynasty}

By studying historical and aesthetic characteristics, it is helpful to fully understand traditional culture, and in this way, we can continue to carry forward the traditional culture for thousands of years. Make use of the current aesthetic concepts to make some creative breakthrough designs for traditional elements, so that it can be connected with the fast-paced society. It must not only be closely connected with life, but also retain the charm of traditional culture, Jewelry designers can not only design fashion trends and jewelry with traditional characteristics.

The gluttony pattern had a mysterious religious color at the time. It was a representative of solemnity. The abstract shape and curve of the gluttony pattern can be used in jewelry, which can break through its own limitations. It is more suitable for the design of necklaces or items. In the use of materials, you can choose tanzanite, sapphire and some atmospheric gems to create a personalized atmosphere, suitable for women in their 30 s to 40 s to attend awards parties, dinners and other formal occasions.

The Hui pattern is a kind of ornamentation of the deformation of the line stripes. It can be used in the design of simple jewelry, but also suitable for the design of faceted gemstone rings and asymmetric earrings. It can be used in the production. Simple ornamentation combined with small-grained gems. For example, aquamarine, morganite, or light-colored tourmaline suitable for office workers around the age of 20 are suitable for daily wear by professional women in the workplace.

The Kuilong pattern and the circular spiral pattern are alternately arranged to form a continuous pattern, which is called the fire dragon pattern. It is more suitable for use in symmetrical item cards and separate pendant designs. In the use of materials, you can choose plain gold materials. The combination of simple materials and complex patterns breaks the single decorative effect. It is suitable for women in their $30 \mathrm{~s}$. Wear on formal 
occasions.

\section{Exploration of design practice}

design description:

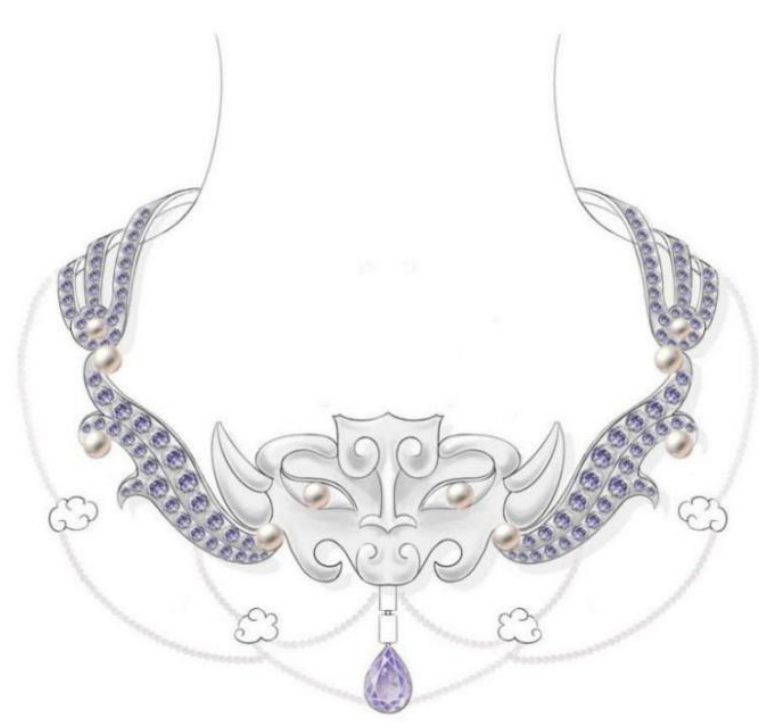

Figure 1: gluttonous

The name of the work: "gluttonous "

Work style: necklace

Production material: 18k gold, tanzanite, pearl, sapphire, enamel

Wearing occasion: large dinner

Design concept: The jewelry is inspired by the decorations on the bronzes of the museum. The typical representative of the Shang Dynasty bronze decorations is adopted as the main design element, the cloud and thunder pattern is used as the embellishment element, and the tanzanite and sapphire are used as the main decoration in the jewelry. Tanzanite is set in clusters on the main stone, and the enamel pattern is used as the embellishment of the entire necklace. This necklace breaks through the traditional design and boldly uses deformed gluttonous ornaments to decorate the necklace for the dinner party. The necklace is not limited to use Modern elements, while abstractly expressing the representative gluttony pattern of the Shang Dynasty, it is said that gluttony is the ninth son of the dragon. It mainly uses gold and silver jewelry and is loved by the Jade Emperor. It not only has a mysterious color, but also Synonymous with luxury, it has a sharp beauty.

\subsection{Personal design work 2}

design description:

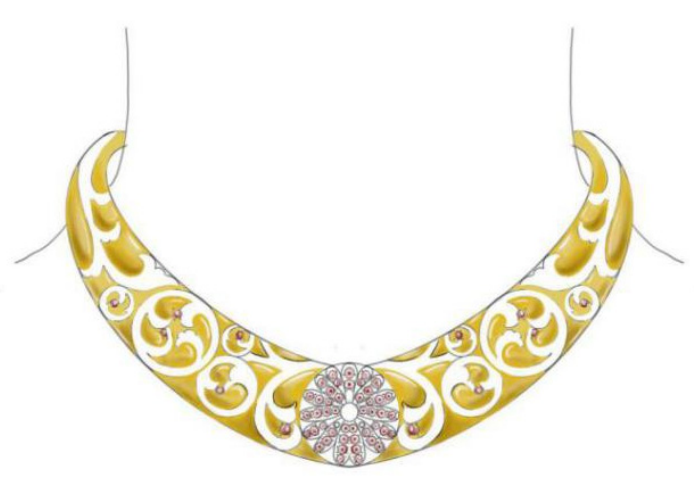

Figure 2: Mind

Design name: "Mind"

Work style: item card

Selection of works: $18 \mathrm{~K}$ gold, diamonds, rubies

Wearing occasion: large dinner

Design concept: The design is inspired by the key pattern on the bronze pattern as the main design element. The key pattern is also called the cloud and thunder pattern. The soft convoluted lines are used to form the pattern. The round cloud and thunder pattern is called the cloud. The pattern and moiré are Chinese auspicious patterns, symbolizing high promotion and wishful thinking. The necklace is embellished with ruby

The overall material is made of $18 \mathrm{k}$ gold. The wearer can show different beauty when wearing it at the dinner party. This uses modern hollowing technology and The perfect combination of traditional patterns can more intuitively bring a visual impact to the viewer, and you can also feel the rich cultural heritage behind Chinese culture.

\section{To in conclusion}

Regarding the application of Shang Dynasty bronze patterns in jewelry design, jewelry designers can better combine modern craftsmanship with traditional patterns, and use the cold materials to give it emotions to show its unique charm. In this form the traditional culture has been carried forward. As a representative of Chinese traditional culture, bronze ornamentation has the imprint of history and culture. At the same time, it also has a better understanding of the story behind the history of the Shang Dynasty, and also has a further in-depth understanding of the jewelry designer industry, allowing future generations to design jewelry to appreciate the story behind the five thousand years of China.

\section{ACKNOWLEDGMENTS}

From the topic selection, to the research, to the writing and revision of the thesis, I can not do without the help of my dear teacher Liu wenming, who constantly guides you and puts forward opinions, so that my thesis can be 
carried out smoothly. Thank you!

\section{Recommended reason}

This is an article about the personalized design of jewelry.

It combines traditional culture, modern intelligent design and

personalized thinking to create 2 personalized works, and study

jewelry from multiple dimensions Innovative design

\section{REFERENCES}

1. Liang Yanmin(2002). Analysis of the straight ribs on the bronzes of the Shang and Zhou Dynasties[J]. "Wen Bo". 2002-2.

2. Fu Yue.(2010). An analysis of the origin of heavy ring patterns on bronzes[J]. Journal of Yunnan Nationalities University (Philosophy and Social Sciences Edition). 2010-3.

3. Lu Qiyuan(2012). The influence and development of decorative patterns in bronzes on modern design[J]. "Hua Zhang".2012-30.

4. Tian Zibing(2004). History of Chinese Arts and Crafts $[\mathrm{M}]$. Shanghai: Oriental Publishing Center. 1985 (reprinted on 2004-7).

5. Zhang Zhongqiang(2015). The decorative art and cultural semantics of the geometric patterns on bronzes in Shang and Zhou Dynasties[J]. "Packaging World".2015-4.

6. Wang Xiaohui.(2014) The enlightenment of Chinese bronze ornamentation to modern design[J]. "Grand View of Fine Arts". 2014- 4.

7. Lu Yongze(2006). Research on the Composition Form of Shang and Zhou Bronze Ornamentation[J]. "Decoration". 2006-11.

8. Zhu Ling(2013). The application of Shang and Zhou bronze ware patterns in the design of modern dining spaces [D]. Dalian: Dalian University of Technology. 2013-10 